\title{
Como os manuais de português para estrangeiros tratam a expressão da futuridade?
}

Elisabeth Penzlien Tafner

Universidade Federal de Santa Catarina - UFSC

\begin{abstract}
A língua portuguesa dispõe de diferentes variedades lingüísticas para expressar a futuridade. Estas são empregadas pelos falantes conforme o interlocutor, local e assunto, porém a quantidade e a descrição dessas formas nos manuais de ensino de português para estrangeiros precisam de maior detalhamento. O trabalho de Tafner (2004) trata de sete formas verbais para a expressão da futuridade, das quais apenas duas foram encontradas nos manuais, o que sugere a necessidade de uma revisão destes, a fim de mostrar o funcionamento do sistema lingüístico do português. Na análise efetuada a partir de alguns manuais, escolhidos aleatoriamente, verificamos que a maioria faz referência apenas ao futuro sintético (-rei) ou à forma vou $-\mathrm{R}$ ou a ambas, mas sem apresentar para o aluno uma descrição detalhada a respeito de sua ocorrência, contextos que propiciam o emprego de uma ou outra forma verbal. Conseqüentemente, a falta dessas observações pode confundir o aluno quando ele tiver contato com outras formas de futuridade não incluídas nos manuais de ensino de PLE.
\end{abstract}

The Portuguese language has different linguistic variants to express future. These variants are used by the speakers according to their interlocutors, the place and subject at hand. However, the quantity and the description of theses forms in Portuguese teaching manuals for foreigners need to be more detailed. Tafner's (2004) study describes seven verb forms to express future. From these seven forms, only two were found in the manuals. This finding suggests the necessity of revising such verb forms in order to show the functioning of the Portuguese linguistic system. In the analysis of some Portuguese teaching manuals randomly selected, it was verified that the majority of them presents only the simple future (-rei) or the perifrastic form with -ir or both, without providing the student a complete description about their occurrence or contexts that foster the use of one or another. Consequently, the absence of these observations can confound the student when he meets other future forms not included in Portuguese teaching manuals for foreigners. 


\section{Introdução}

A competência comunicativa implica saber uma língua para poder usá-la criativamente em diversas situações sociais. Nesse sentido, observamos que o falante vai precisar adequar sua fala conforme o interlocutor, o lugar e o assunto em questão. Cada situação social exige uma variedade lingüística adequada e isso suscita questões bastante complexas, que contribuem para a alteração do discurso dos falantes. Esse quadro fica ainda mais delicado quando relacionado ao ensino de uma segunda língua (L2). O aluno, de uma L2, pode se sentir bastante inseguro ao verificar que existem discrepâncias entre o que é exposto nos materiais adotados para ensino de uma LE e o que, de fato, é empregado pelos falantes nativos dessa LE. É o que parece ocorrer no ensino de português para estrangeiros (PLE): não tem se refletido nos materiais didáticos para ensino dessa língua.

Alguns desses manuais são bastante precários na quantidade de variedades lingüísticas apresentadas e sua respectiva descrição, pelo menos no que diz respeito ao tempo verbal futuro do presente do indicativo. Neste artigo, a partir do trabalho de Tafner (2004), examinaremos quais são as formas verbais presentes para a expressão da futuridade em alguns manuais para o ensino de PLE, com o objetivo de mostrar que eles precisam de um maior aprofundamento na descrição dos usos dessas formas verbais. Pretendemos, assim, contribuir no processo de ensino e de aprendizagem de português para estrangeiros, oferecendo explicações para algumas formas em uso que, por vezes, não são citadas nesses materiais ou nas gramáticas tradicionais.

\section{O fenômeno da variação entre as formas de futuro}

Tafner (2004) trata do estudo de sete formas verbais alternantes (descritas adiante) para a expressão da futuridade, a partir de dados das sessões plenárias dos Estados do Rio de Janeiro, São Paulo, Paraná, Santa Catarina e Rio Grande do Sul:

* futuro sintético - FS:

(1) Porque se trata do projeto mais importante que esta Casa votará até o final do ano. (PR - 104ord02)

* ir (presente) + verbo principal (infinitivo) - vou $-R$ :

(2) Portanto, o justo, o correto seria a mobilização da própria reitoria da Udesc e de todos os que estão participando do movimento para levar a Udesc para o Oeste do Estado terem 
uma conversa muito franca com o Governador eleito, para saber se ele vai cumprir aquilo que o atual Governador pretende fazer ou deixar para o outro. (SC - 89ord02)

* ir (futuro) + verbo principal (infinitivo) - irei- $R^{1}{ }^{1}$

(3) O secretário de obras irá entregar o relatório esta semana. (PR $-1040 \mathrm{rd} 02)$

* estar (futuro) + verbo principal (gerúndio) - estarei - NDO:

(4) [...] na próxima semana, estarei indo para Brasilia, porque são inúmeros os problemas que o Paraná enfrenta. (PR -101ord02)

* ir (presente) + estar (infinitivo) + verbo principal (gerúndio) - vou estar-NDO:

(5) Se votarmos o relatório, vamos estar aprovando 21 secretarias. ( $\mathrm{SC}-07 \mathrm{ex} 03)$

* estar (presente) + verbo principal (gerúndio) - estou - NDO:

(6) [...] gostaria que V. Exa. e o deputado C. assinassem comigo a Comissão de Segurança: estou encaminhando ao secretário J. T., em 48 horas. (PR - 103ord 02)

* presente - presente:

(7) Amanhã, a Comissão de Finanças deve apreciar o Orçamento de 2003. (SC 92ord02)

As formas verbais que exprimem o tempo futuro do presente no referido trabalho são analisadas sob uma perspectiva sociofuncionalista. No domínio da sociolingüística laboviana (Cf. WEINREICH; LABOV; HERZOG, 1968), a autora trabalha com a noção de regra variável: quando há duas ou mais formas distintas de se transmitir o mesmo significado referencial, em um mesmo contexto, elas podem ser tomadas como variantes lingüísticas. $\mathrm{E}$, ciente de que lida com uma função comunicativa/discursiva, a autora também mergulha no quadro do Funcionalismo Lingüístico (FLEISHMAN, 1982; GIVÓN, 2001). Porém, visto que a função de expressar o futuro do presente é prioridade e que camadas/variantes parecem estar disputando essa função, o estudo assumiu uma postura mais inclinada ao funcionalismo.

${ }^{1}$ Devido ao reduzido número de dados, apenas $33(5 \%)$, irei- $R$ teve um tratamento diferenciado. Veja mais detalhes a respeito em Tafner (2004). 


\section{Procedimentos metodológicos}

Nas sessões plenárias pesquisadas, obtivemos 688 dados que expressam futuridade.

Para estabelecer a distribuição de uso das sete formas variantes e descrever seus contextos, utilizou-se o pacote estatístico VARBRUL $2 S$ (PINTZUK, 1988). Neste trabalho, apresentamos apenas os resultados para a variável fonte do dado.

\section{Resultados e discussão}

Dentre as sete formas variantes, observou-se uma relativa predominância do FS, conforme se observa na TAB. 1 .

TABELA 1

Distribuição de uso das variantes que expressam tempo futuro nas sessões plenárias

\begin{tabular}{ll|cc}
\hline & Variantes & Número de dados & \% \\
\hline (a) & Futuro Sintético (FS ) & $\mathbf{3 5 2}$ & 51 \\
(b) & Vou $-R$ & 216 & 31 \\
(c) & Locuções estar $-N D O^{2}$ & 66 & 10 \\
(d) & Presente & 54 & 8 \\
\hline \multicolumn{2}{c|}{ Total } & 688 & 100 \\
\hline
\end{tabular}

Os resultados da TAB. 1 convergiram para as expectativas da autora em relação à variante canônica. A hipótese era de que houvesse uma significativa concentração de dados no $F S$, dado o grau de formalidade inerente da amostra. Os parlamentares, em função do caráter público das sessões, possuem uma certa preocupação com a norma culta, uma vez que sabem que sua fala está sendo acompanhada tanto por uma platéia atenta e bastante crítica quanto pela consciência de que essa fala ficará registrada nos anais da Casa ou ainda que está sendo acompanhada via rádio e TV. Esses fatos contribuíram para que os dados tivessem um caráter relativamente formal.

Os números da TAB. 1 coincidem de certa forma com os resultados encontrados por Santos (1997)e Santos (2000) que lidaram com dados

\footnotetext{
${ }^{2}$ As locuções estar - NDO incluem as formas estarei - NDO, vou estar - NDO (apenas três dados) e estou-NDO(apenas dois dados).
} 
portadores de algum traço de formalidade. A primeira autora trabalhou com textos de escrita culta e transcritos de fala, provenientes dos periódicos Diário do Congresso Nacional e revista Semanal IstoÉ, e constatou que o futuro simples (-rei) foi o mais recorrente em ambos. Porém, foi possível fazer a seguinte correlação: nas situações de maior formalidade, como nas sessões do Diário, temos o futuro simples e, nas de menor formalidade, como na revista, temos a perífrase, aqui correspondente a nossa variante $v o u-R$. A segunda autora trabalhou com duas amostras, uma de natureza informal e outra de natureza formal. Nesta última, Santos (2000) encontrou uma distribuição bastante interessante: 30\% de uso do futuro simples equiparado aos 30\% de uso da forma perifrástica. Porém ambos são superados pelo uso do presente com sentido de futuro (saio), 40\%. Com relação à presença das locuções estar - NDO, a TAB. 1 mostra que, mesmo em pequena escala, essas formas estão em variação com o FS e com vou$R$, e, em determinados contextos, com a forma verbal de presente, para expressão da futuridade, conforme afirma Henriques (2000, p. 3) “à tradicional substituição de 'enviaremos' por 'vamos enviar', acrescentamse hoje as formas 'estaremos enviando' ou 'vamos estar enviando', o que representa duas variantes de idéias em processo, sem contudo a carga semântica de futuro imediato". Responde-se, assim, a uma das questões centrais do trabalho de Tafner (2004). O número reduzido de ocorrências com estar-NDOnão era o esperado, mas permite observar, de certa forma, qual é o comportamento desse grupo de variantes em contraste às demais formas de futuro estudadas pela autora. Trabalhos sobre o tempo verbal futuro do presente como o de Baleeiro (1988), Santos (1997), Poplack e Turpin (1999), Gibbon (2000), Santos (2000), Silva (2002), dentre outros, nada ou quase nada dizem com relação ao comportamento das variantes estar - NDO para expressão do futuro.

O grupo fonte do dado indicou que o emprego das variantes nos Estados apresentou diferenças significativas, evidenciando que as atitudes dos falantes diante das formas não são as mesmas. Conseqüentemente, a formalidade que esperávamos encontrar não é a mesma em todos os cinco Estados cujas sessões plenárias foram registradas para análise de dados de pesquisa, conforme evidencia a TAB. 2 a seguir: 
TABELA 2

Influência da fonte do dado sobre as variantes

\begin{tabular}{|c|c|c|c|c|c|c|c|c|c|c|c|c|}
\hline \multirow{3}{*}{ Fatores } & \multicolumn{12}{|c|}{ Variantes } \\
\hline & \multicolumn{3}{|c|}{ estar-NDO } & \multicolumn{3}{|c|}{ FS } & \multicolumn{3}{|c|}{ vou $-R$} & \multicolumn{3}{|c|}{ Presente } \\
\hline & $\begin{array}{l}\text { Freqüência } \\
\text { Aplic./Total }\end{array}$ & $\%$ & PR & $\begin{array}{l}\text { Freqüência } \\
\text { Aplic./Total }\end{array}$ & $\%$ & PR & $\begin{array}{l}\text { Freqüência } \\
\text { Aplic./Total }\end{array}$ & $\%$ & PR & $\begin{array}{l}\text { Freqüência } \\
\text { Aplic./Total } \\
\end{array}$ & $\%$ & PR \\
\hline$R S$ & $16 / 130$ & 12 & 0,61 & $89 / 130$ & 68 & 0,65 & $10 / 130$ & 8 & 0,20 & $9 / 130$ & 7 & $(0,48)$ \\
\hline$S C$ & $10 / 190$ & 5 & 0,40 & $81 / 190$ & 43 & 0,38 & $74 / 190$ & 29 & 0,67 & $17 / 190$ & 9 & $(0,55)$ \\
\hline$P R$ & $24 / 104$ & 23 & 0,77 & $45 / 104$ & 43 & 0,41 & $27 / 104$ & 26 & 0,49 & $4 / 104$ & 4 & $(0,33)$ \\
\hline$S P$ & $9 / 144$ & 6 & 0,42 & $71 / 144$ & 49 & 0,51 & $42 / 144$ & 29 & 0,56 & $16 / 144$ & 11 & $(0,61)$ \\
\hline$R J$ & $7 / 120$ & 6 & 0,38 & $66 / 120$ & 55 & 0,59 & $30 / 120$ & 25 & 0,53 & $8 / 120$ & 7 & $(0,47)$ \\
\hline Total & $66 / 688$ & 10 & & $352 / 688$ & 51 & & $183 / 688$ & 27 & & $54 / 688$ & 8 & \\
\hline $\begin{array}{l}\text { Ordem } \\
\text { de seleção } \\
\text { Estatística }\end{array}$ & \multicolumn{3}{|c|}{$1^{\circ}$ grupo selecionado } & \multicolumn{3}{|c|}{$3^{\circ}$ grupo selecionado } & \multicolumn{3}{|c|}{$2^{o}$ grupo selecionado } & \multicolumn{3}{|c|}{$\begin{array}{c}\text { O grupo não foi } \\
\text { selecionado }\end{array}$} \\
\hline
\end{tabular}

No Rio Grande do Sul $(0,65)$, principalmente, e no Rio de Janeiro $(0,59)$ percebemos que os parlamentares, para a expressão da futuridade, ainda tendem a empregar com maior freqüência a variante canônica. São Paulo $(0,51)$ é o local onde o futuro do presente disputa a expressão da futuridade de forma mais acirrada com as demais variantes. Já os parlamentares paranaenses $(0,41)$ e catarinenses $(0,38)$, inclinam-se a não empregar a forma verbal canônica durante suas sessões.

\section{A situação dos manuais}

Retomando a discussão sobre os manuais, resumimos a seguir o que encontramos sobre o tempo verbal futuro do presente do indicativo em alguns materiais consultados. A escolha desses manuais foi aleatória.

Lima e Iunes (1981) trazem o futuro do presente ao exibir os tempos do modo indicativo, mostrando apenas a conjugação do verbo sair na forma sintética. Além disso, os exercícios propostos nesse material didático podem causar algum tipo de dificuldade, à medida que algumas atividades pedem ao aluno que "complete com o verbo no tempo adequado", mas acabam envolvendo formas de futuridade com verbo modal (8) ou locuções ( vouR) (9) sem fazer nenhum comentário sobre esses possíveis usos.

(8) "(cair) Cuidado com os buracos. Você pode ..."

(9) "(atrair) Não vou entrar neste cinema, pois este gênero de filme não me...."

Forst (1989), no Novo manual do professor, elaborado com a colaboração de Lima e Iunes, traz tanto a forma vou $-R$ (classificada como 
futuro imediato pelas autoras) quanto a forma sintética de futuro, porém o tratamento dado a essas formas não excede a realização de exercícios de repetição oral de estruturas ou exercícios escritos.

Laroca, Bara e Pereira (1992) tratam do futuro do presente mostrando apenas a conjugação desse tempo a partir da forma sintética. Como exercício, as autoras solicitam que o aluno complete com verbos no futuro do presente uma carta (o interlocutor é provavelmente um amigo) e, em seguida, há a mesma atividade a ser executada em um diálogo entre uma moça e uma cartomante.

Marchant (1994), num manual voltado para o público infanto-juvenil, trata do futuro do presente, partindo de um texto relativo a uma excursão, em que há uma série de frases no futuro, todas elas empregando vou-R: "minha turma vai fazer uma excursão...", "vamos chegar...", "as comissões vão ter...", "a comissão de alimentação vai estabelecer...". A autora solicita ao aluno que faça um exercício passando as frases do pretérito perfeito para o futuro:

(10) "Eu comprei um livro ontem. Eu ... comprar um livro amanhã".

(11) "Você chegou atrasado ontem. Você ... chegar atrasado amanhã"?

(12) "Ela ficou em casa ontem. Ela ... ficar em casa depois de amanhã"?

As demais frases seguem da mesma forma, sempre pedindo para que o aluno use $v o u-R$ numa frase em que há o uso de marcas temporais.

Já num manual dedicado ao nível avançado, Marchant (1997) tem como foco principal o trabalho com verbos e oferece algumas explicações mais amplas, como o conceito de locução verbal: "combinação das diversas formas de um verbo (auxiliar) com o infinitivo, gerúndio ou particípio de outro verbo, que se chama principal. Na locução verbal, é somente o verbo auxiliar que faz a flexão de pessoa, número, tempo e modo" (MARCHANT, 1997, p. 87). A autora, tendo apresentado o conceito de locuções verbais, poderia aproveitá-lo, mostrando a riqueza de formas verbais existentes na língua portuguesa capazes de atuar na função de expressar futuridade, permitindo ao aluno começar a ter contato com formas alternantes para uma mesma função e assim reconhecer a existência do fenômeno da variação.

O único exemplo oferecido é de futuro do presente composto:

(13) "Hoje à noite já terei (haverei) feito o trabalho". 
Adiante Marchant (1997) explica os modos e tempos, referindo-se ao futuro do presente simples como capaz de representar uma ação futura (14) "Estudarei amanhã." O futuro do presente composto, "expressa um fato que é futuro em relação ao momento de fala, mas passado em relação a outra circunstância" (15) "Amanhã, às 10h, já terei feito o trabalho." (MARCHANT, 1997, p.114). Curiosamente, a autora não inclui, nesta obra, a forma $v o u-R$, citada em seu manual de (1994).

Fontão e Coudry (2000), num manual destinado ao público jovem, apresentam o futuro a partir de um texto sobre uma festa junina. Há uma pequena explicação comentando que "esse texto mostra como usamos o futuro em português” (FONTÃO; COUDRY, 2000, p.10). Depois, temos um exercício em que o aluno deve relacionar os verbos em que houve o uso desse tempo, resultando em algo como:

(16) "Na semana que vem nós vamos fazer uma festa junina".

(17) "Vai ser no dia vinte e oito de junho".

(18) "Cada aluno vai trazer".

(19) "Amanhã eu vou a casa da Beatriz depois do almoço".

Contudo os autores fazem uma interessante observação quanto ao emprego do verbo ir, comentando que, quando usado no futuro, ele dispensa o infinitivo, apresentando as mesmas formas no presente e no futuro.

(20) "Eu sempre vou a praia com meu irmão (presente)".

(21) "Eu vou à praia com meu irmão no fim de semana que vem (futuro)".

Ponce, Burim e Florissi (2003, p.102) afirmam que "em português, podemos dar idéia de futuro de duas formas diferentes. Nesta, unidade, estudaremos um dos dois casos." Os exemplos a seguir são das autoras:

(22) "Amanhã vou fazer um passeio com a escola."

(23) "Vamos visitar o zoológico."

Adiante, nessa obra didática, elas citam o futuro sintético, mas, antes, comentam que "Ir + verbo no Infinitivo é mais usado coloquialmente" e sobre o futuro sintético, elas afirmam que se trata de "verbo conjugado na forma do Futuro do Presente, citando este exemplo: Paula e Roberto também irão ao show amanhã." (PONCE; BURIM; FLORISSI, 2003, p. 119). 
Esse foi o único manual em que se percebeu uma certa preocupação das autoras em situar o aluno quanto ao contexto em que uma determinada forma é mais freqüente. Ainda não é o suficiente, mas já é um indício de que os materiais precisam complementar a descrição das formas que costumam apresentar.

Diante disso, se retomarmos os exemplos de futuro sintético dos vários autores, percebemos que grande parte deles reproduz situações de fala, num contexto informal (sem hierarquia entre os interlocutores, em situações em que não há provavelmente preocupação com a norma considerada culta da língua portuguesa), isto é, contextos mais propícios à ocorrência de $v o u-R$ do que propriamente a do futuro sintético. Essa análise parece-nos coerente, em função dos resultados encontrados por Gibbon (2000). A autora trabalhou com o banco de dados do Projeto Varsul (36 informantes nativos de Florianópolis), encontrando apenas 1\% de uso da forma canônica em dados de fala. Nessa amostra, dentre as formas estudadas - o futuro simples (farei), o presente (faço) e a perífrase (vou fazer) - a perífrase (vou fazer) foi a forma mais utilizada, refletindo a adequação das formas de futuro em função do contexto (entrevistas sociolingüísticas). Os únicos autores que pedem o uso da forma sintética na modalidade escrita (numa carta, transcrita adiante neste artigo) são Laroca, Bara e Pereira (1992). A razão para isso talvez seja o fato de que a língua escrita favoreça essa forma:

Cristina: [...] (chegar/eu) no próximo sábado com a família. [...] (ficar/nós) uma semana com vocês. As crianças [...] (passar) o resto das férias ai. Lídia [...] (seguir) viagem para o Nordeste e [...] conhecer as suas capitais. $\mathrm{Na}$ volta das férias, [...] (visitar/nós) os nossos parentes do interior. Um abraço do Roberto.

A situação descrita pela carta não parece exigir o uso da forma sintética, forma canônica de futuro, privilegiada pelas gramáticas normativas e pela maioria dos manuais aqui analisados. O primeiro indício que nos aponta nessa direção é não haver o uso de nenhum pronome de tratamento entre os interlocutores, ou seja, aparentemente não há hierarquia entre eles; o relato comenta a seqüência de eventos das férias de Roberto (o assunto tratado não parece exigir nenhum tipo de formalidade). Diante desses fatos, supomos que o uso de $v o u-R$ seria o mais adequado, até porque, no enunciado "e... conhecer as suas capitais" os autores, mesmo não tendo mostrado para o aluno a forma $v o u-R$, sugerem o seu uso (ou então temos aqui um engano no momento da elaboração do exercício). 
Em quase todos os exemplos constantes nos materiais didáticos analisados, o foco está no uso do futuro sintético ou $v o u-R$ com o auxílio de marcas temporais explícitas, com exceção do texto relativo à festa junina (FONTÃO; COUDRY, 2000) no qual, devido à progressão do texto, notase que todas as situações têm projeção futura. O segundo exemplo de Ponce, Burim e Florissi (2003) também não faz uso de marcas temporais, visto que o contexto anterior já garante a idéia de futuridade. O uso de marcas temporais poderia servir como ponto de partida para comentar a possibilidade de expressão da futuridade a partir de outras formas como o presente com o futuro, por exemplo. Trilhando esse caminho, certamente encontraríamos espaço para nos referirmos às condicionais ou aos verbos modais, contextos que favorecem a ocorrência das formas de futuridade.

Sintetizando, a busca nesses materiais revelou que eles restringem as formas de expressão do futuro do presente, fazendo referência somente ao futuro sintético (-rei) ou a forma vou $-R$ ou a ambas, mas sem informar o aluno que fatores contribuem para seu uso.

A ausência de comentários, nos manuais consultados para análise, sobre outras formas lingüísticas para indicar o tempo verbal futuro do presente, como o presente indicando futuro, ire $-R$, vamos estar-NDO ou estaremos - NDOe de observações sobre os contextos que propiciam seu uso podem confundir o aluno quando ele tiver contato com essas formas de futuridade. Nesse sentido, a dissertação de Tafner (2004) oferece algumas contribuições relevantes, como:

* descrição de uma análise sociofuncionalista do tempo futuro, utilizando dados de fala, através do controle de grupos de fatores lingüísticos e extralingüísticos;

* proposta para explicar o fenômeno da variação entre o FS, vou $-R$, o presente e as locuções estar- NDO;

* reflexão sobre a possibilidade de se considerar as locuções estar - NDO como formas regulares na língua portuguesa para expressão tempo verbal futuro do presente.

\section{Considerações finais}

Os manuais de ensino de português para estrangeiros analisados referem-se ao estudo do tempo verbal futuro do presente, empregando apenas o futuro sintético e $v o u-R$, não atentando para as demais formas possíveis e em uso de futuridade. Além disso, a descrição sobre o 
funcionamento dessas formas, quando comentada, é bastante superficial. O confronto entre o conteúdo dos manuais e a exposição feita por Tafner (2004) mostra como esses manuais precisam ser enriquecidos. Das sete formas comentadas pela autora, os manuais citam apenas duas, oferecendo pouca ou nenhuma informação adicional. O aluno precisa ter contato com o maior número possível de variedades lingüísticas a fim de poder se expressar da melhor forma possível conforme a situação. Para isso, ele precisa conhecer todas as formas de que a língua que está aprendendo dispõe e em que situações essas formas lingüísticas são mais adequadas. Portanto, informações como os contextos e freqüência de uso das formas possíveis são imprescindíveis nesse material, cuja missão é mostrar o funcionamento do sistema lingüístico do português.

A inclusão de informações de natureza sociofuncionalista, como aquelas encontradas em Tafner (2004), poderia contribuir tanto para o ensino das formas já citadas pelos materiais quanto para a inclusão de outras como irei-R, o presente como futuro e, principalmente, as locuções estar - NDO. Isso porque não só os manuais para o ensino de português para estrangeiros como também os livros didáticos raramente citam as locuções estar-NDOcomo possibilidade de uso.

\section{Referências Bibliográficas}

BALEEIRO, M. I. O futuro do presente no português culto de São Paulo. 1988. Dissertação. (Mestrado em Lingüística) - Universidade Estadual de Campinas, Campinas, 1988.

FLEISHMAN, S. The future in thought and language. Cambridge: Cambridge University Press, 1982.

FONTÃO, E.; COUDRY, P. Sempre amigos: fala Brasil para jovens. Campinas, SP: Pontes, 2000.

FORST, G. Falando... Lendo... Escrevendo: português para estrangeiros: novo manual do professor. São Paulo: EPU, 1989.

GIBBON, A. O. A expressão do tempo futuro na lingua falada de Florianópolis: gramaticalização e variação. 2000. Dissertação (Mestrado em Letras/Lingüística) - Faculdade de Letras, Universidade Federal de Santa Catarina, Florianópolis, 2000.

GIVON, T. Syntax: an introduction. v. I. Amsterdam; Philadelphia: J. Benjamins, 2001. 
HENRIQUES, C. C. Sintaxe Discursiva, Aspecto, Gerúndio e Gerundismo. ABP - Revista do Centro do Mundo Lusofônico, v.1, n.2, Köln: 2000, p. 16-24.

LAROCA, M. N. de C.; BARA, N.; PEREIRA, S. M. da C. Aprendendo português do Brasil: um curso para estrangeiros. Campinas, SP: Pontes, 1992.

LIMA, E. E. O. F.; IUNES, S. A. Falando... Lendo... Escrevendo: português: um curso para estrangeiros. São Paulo: EPU, 1981.

MARCHANT, M. Português para estrangeiros: infanto-juvenil. Porto Alegre: Age, 1994.

. Português para estrangeiros: nível avançado. Porto Alegre: Age, 1997.

PINTZUK, S. VARBRUL Program. Philadelphia: University of Pennsylvania. Impresso. 1988

PONCE, M. H. O. de; BURIM, S. R. B. A; FLORISSI, S. Tudo bem: português para a nova geração. vol. 1. São Paulo: Special Book Services Livraria, 2003.

POPLACK, S.; TURPIN, D. Does the futur have a future in (Canadian) french? Probus, v.11, n. 1, p. 133-164, 1999.

SANTOS, A. M. dos. O futuro verbal no português do Brasil em variação. 1997. Dissertação (Mestrado em Lingüística) - Faculdade de Letras, Universidade de Brasília, Brasília, 1997.

SANTOS, J. R. dos. A variação entre as formas de futuro do presente no português formal e informal falado no Rio de Janeiro. 2000. Dissertação (Mestrado em Lingüística) - Faculdade de Letras, Universidade Federal do Rio de Janeiro, 2000.

SILVA, A. A sobreposição modal em ir + infinitivo. In: ABAURRE, M.B.M.; RODRIGUES, A.C.S. (Org.). Gramática do Português Falado. Campinas, SP: Editora da Unicamp, 2002. p. 479-495.

TAFNER, E. P. As formas verbais de futuridade em sessões plenárias: uma abordagem sociofuncionalista. 2004. Dissertação (Mestrado em Lingüística) - Faculdade de Letras, Universidade Federal de Santa Catarina, Florianópolis, 2004.

WEINREICH, U.; LABOV, W.; HERZOG, M. I. Empirical foundations for a theory of language change. In: LEHMANN, W. P.; MALKIEL, Y. (Ed.) Directions for historical linguistics. Austin: University of Texas Press, 1968. 